\title{
OPTIMASI PENEMPATAN MENARA BTS MENGGUNAKAN QUANTUM-BEHAVED PARTICLE SWARM OPTIMIZATION
}

\author{
Moh Fatkhur Rohman*, Faqih Rofii , dan Fachrudin Hunaini \\ Jurusan Teknik Elektro, Fakultas Teknik, Universitas Widyagama \\ *Corresponding author, e-mail : fatkhurrohman.mohamad@gmail.com
}

\begin{abstract}
Abstrak - Universal Mobile Telecomunication System (UMTS) saat ini dipandang sebagai sebuah sistem impian yang menggantikan Global System for Mobile Communication (GSM) dan merupakan salah satu evolusi generasi ketiga (3G) dari jaringan mobile. Salah satu komponen pendukung jaringan UMTS adalah Node B, Node B dapat dianalogikan sebagai BTS. Seiring perkembangan kebutuhan pelanggan yang semakin meningkat, kebutuhan akan BTS(Node B) semakin bertambah, hal ini menyebabkan banyaknya jumlah menara BTS da menyebabkan pemandangan yang kurang bagus bagi visualisasi kota.oleh karena itu perlu dilakukan optimisasi penempatan menara BTS. Salah satu metode untuk mengoptimasi adalah Quantum-behaved Particle Swarm Optimization. Maka dalam penelitian ini akan dirancang simulasi optimasi penempatan BTS menggunakan QPSO dengan parameter yang akan dioptimasi adalah Coverage Area dan Trafik. Dari hasil penelitian yang dilakukan, Algoritma QPSO mampu mengurangi jumlah BTS dari 55 BTS menjadi 43 BTS.
\end{abstract}

Kata Kunci : UMTS900, BTS, QPSO

\begin{abstract}
Universal Mobile Telecommunications System ( UMTS ) is currently regarded as a dream system that replaces the Global System for Mobile Communication ( GSM ) and is one of the evolution of third generation ( $3 \mathrm{G}$ ) of mobile networks. One componentof UMTS network is Node B, Node B can be analogous to the BaseTransceiver Station. Along with the increasing customer need, there need for increasing number of Node B and that can divided the visualize of the city and need optimization of tower placement .Quantum - behaved Particle Swarm Optimization. So in this research be designed simulation optimization placement of base stations using QPSO with parameters to be optimized is the Coverage Area and Traffic .QPSO algorithm can reduce the number of base stations from 55 to 43 BTS.
\end{abstract}

Keyword : UMTS900, Base Tranceiver Station, QPSO

Copyright $\odot 2016$ JNTE. All rights reserved

\section{PENDAHULUAN}

Perkembangan permintaan pelanggan jaringan seluler saat ini memerlukan banyaknya kebutuhan Node $B$ (BTS) untuk melayani permintaan tersebut. Meningkatnya jumlah menara BTS tersebut akan menimbulkan efek bagi pemandangan kota, maka perlu dilakukan langkah-langkah optimasi penataan letak BTS. Performansi penempatan BTS ditentukan oleh daya cakup wilayah (coverage area) yang dihasilkan dan tingkat layanan trafik[1].

Optimasi penempatan menara BTS selama ini menggunakan metode algoritma genetika. Algoritma ini didasarkan pada proses genetik yang ada dalam makhluk hidup, yaitu perkembangan generasi dalam sebuah populasi yang alami, secara lambat laun mengikuti prinsip seleksi alam atau siapa yang kuat, dia yang bertahan (survive). Dengan meniru teori evolusi ini, Algoritma Genetika dapat digunakan untuk mencari solusi permasalahan-permasalahan dalam dunia nyata [2].

Dinamika optimasi yang berkembang salah satunya adalah Particle Swarm Optimization (PSO). PSO adalah teknik optimasi yang dikembangkan oleh Eberhart dan Kennedy pada tahun 1995[3]. PSO merupakan teknik optimasi yang menerapkan metode pencarian makanan oleh sekelompok burung maupun ikan pada suatu ruang permasalahan. Kelemahan yang terdapat pada PSO biasa adalah cenderung untuk mencapai konvergensi pada local optima yang terlalu cepat. Khususnya pada permasalahan yang tidak teratur. Sehingga menyebabkan hasil hanya merupakan sebuah local optima, belum merupakan global optima [3]. Dalam perkembangan PSO, dikenal metode Quantumbehaved Particle Swarm Optimization (QPSO) . QPSO memiliki kemampuan untuk mencari nilai 
konvergen secara lebih efektif daripada PSO akan tetapi memiliki parameter kontrol yang lebih sedikit[4]. Oleh karena itu, pada penelitian ini akan dilakukan perencanaan dan simulasi penempatan Menara BTS pada BTS menggunakan metode Quantum-behaved Particle Swarm Optimization dengan software matlab untuk perhitungannya sehingga penempatan BTS sehingga dapat mengurangi maraknya jumlah menara BTS dan menigkatkan efisiensi biaya. Tujuan dari penelitian ini adalah untuk mengoptimalkan penempatan Menara Base Transceiver Station sehingga dapat mengurangi maraknya jumlah menara BTS.

\section{TINJAUAN PUSTAKA}

\subsection{UMTS}

UMTS saat ini dipandang sebagai sebuah sistem impian yang menggantikan Global System for Mobile Communication (GSM). UMTS merupakan salah satau evolusi generasi ketiga (3G) dari jaringan mobile. Transmisi peningkatan jaringan mencapai kecepatan sampai 2 Mbps per pemakai mobile dan menetapkan suatu standard penjelajahan yang global. UMTS disebut juga sebagai Wideband Code Division Multiple Access (W-CDMA). standar terakhir dari worldwide tunggal untuk seluruh telekomunikasi mobile, International Mobile Telecommunications- 2000 (IMT2000)[5].

Salah satu komponen pendukung jaringan UMTS adalah node B. Node B merupakan unit fisik dari transmisi resepsi radio dengan menggunakan sel[5]. Node B dapat dianalogikan sebagai BTS pada jaringan GSM. Node B juga beparsitipasi dalam kontrol daya, sebagai sesuatu yang memungkinkan untuk penyesuaian daya memakai perintah downlink (DL) transmission power control (TCP) melalui innerloop power control berdasarkan pada informasi uplink (UL) TCP. Nilai-nilai yang sudah dikenal dari inner-loop power control berasal dari RNC melalui outer-loop power control.

\subsection{Perencanaan Jaringan Komunikasi Seluler}

\subsubsection{Penentuan Area Layanan}

Berdasarkan kepadatan penduduk dan tingkat aktivitas penduduknya wilayah dapat dibagi menjadi dua jenis, yaitu wilayah urban dan suburban. Wilayah urban adalah wilayah yang memiliki tingkat kepadatan penduduk dan aktivitas manusia yang tinggi dibandingkan daerah-daerah sekitarnya. Wilayah suburban adalah wilayah yang memiliki tingkat kepadatan penduduk yang lebih rendah daripada daerah urban.

\subsubsection{Perhitungan Jumlah Pelanggan}

Kepadatan penduduk menentukan seberapa besar trafik yang harus disediakan oleh suatu operator jaringan seluler. Jaringan UMTS yang akan dibangun harus mampu mengantisipasi besarnya jumlah pelanggan untuk beberapa tahun ke depan. Maka untuk mengantisipasi jumlah pelanggan selama periode tersebut diperlukan estimasi pertumbuhan jumlah pelanggan, yang dapat dihitung dengan persamaan berikut [1]:

$$
U n=(1+f p) n
$$

Dimana:

Un : jumlah user total setelah tahun ke-n

Uo : jumlah user saat perencanaan

$f p$ : faktor pertumbuhan

$n \quad$ : jumlah tahun prediksi

\subsubsection{Perhitungan Offered Bit Quantity (OBQ)}

OBQ adalah total bit throughput per $\mathrm{km}^{2}$ pada jam sibuk. OBQ selama jam sibuk untuk suatu area tertentu dihitung berdasarkan beberapa asumsi, yaitu penetrasi user, durasi panggailan efektif, Busy Hour Call Attempt (BHCA), dan bandwidth dari layanan. Besarnya nilai OBQ dapat dihitung dengan persamaan berikut [6]:

$$
\sum O B Q=\frac{\sigma X \rho X d B H C A X B W}{3600}
$$

Dimana:

$\begin{array}{ll}\boldsymbol{\sigma} & : \text { Kepadatan pelanggan potensial } \\ & \text { dalam suatu daerah }\left(\text { user } / \mathrm{km}^{2}\right) \\ \boldsymbol{\rho} & : \text { Penetrasi pengguna tiap layanan } \\ \boldsymbol{d} & : \text { Durasi panggilan efektif }(\mathrm{s}) \\ \text { BHCA } & : \text { Busy Hour Call Attempt }(\mathrm{call} / \mathrm{s}) \\ B W & : \text { Bandwidth tiap layanan }(\mathrm{Kbps})\end{array}$

\subsubsection{Perhitungan Kapasitas Kanal per BTS}

Kapasitas yang dimaksud adalah jumlah pelanggan yang dapat dilayani dalam suatu BTS/sel. Rumus yang digunakan untuk menghitung jumlah kanal per sel dengan satu frekuensi pembawa adalah [1]: 


$$
N \text { sel }=\frac{W / R}{\left[\frac{E b}{N o}\right]} \frac{\beta}{\alpha[1+f]}
$$

Dimana:

$\begin{array}{ll}\mathrm{R} & : \text { Data rate }(\mathrm{Kbps}) \\ \mathrm{Eb} / \mathrm{No} & : \text { Energi bit per noise }(\mathrm{dB}) \\ \mathrm{W} & : \text { Bandwidth(Mbps) } \\ \alpha & : \text { Activity factor } \\ \beta & : \text { Gain sektorisasi antena } \\ f & : \text { Faktor interferensi }\end{array}$

2.2.5. Perhitungan Jumlah Sel yang Dibutuhkan
Untuk menghitung jumlah sel/BTS yang diperlukan, maka terlebih dahulu dihitung total luas coverage [1]:

Luas Coverage BTS $=\frac{\text { Kapasitas Kanal }}{\sum O B Q}$

Setelah itu, barulah dapat dihitung jumlah sel/BTS yang dibutuhkan untuk masing-masing jenis wilayah dengan membagi luas area dengan luas coverage per sel.

\subsubsection{Model Propagasi}

Performansi jaringan dipengaruhi oleh model propagasi yang digunakan, karena model propagasi digunakan untuk memprediksi besarnya interferensi yang terjadi.

\subsubsection{Model Hata-Okumura}

Rumus model propagasi Okumura-Hatta adalah [1]:

Wilayah urban:

$L_{P L}=69,55+26,16 \log 10(f)-13,82 \log 10(H b)-a$

$(H m)+[44,9-6,55 \log 10(H b) \log 10(r)$

Wilayah Suburban :

$L_{\mathrm{P} L}=L_{U r b a n}-2\left[(f / 28)^{2}-5,4\right] d B$

Dimana Lu : Mean Path Loss (dB)

f : frekuensi $(\mathrm{MHz})$

$H \quad$ : tinggi antena base station (m)

d : jarak dari base station $(\mathrm{Km})$

$\mathrm{Hm}$ : koreksi tinggi antena penerima terhadap tinggi standar $(\mathrm{dB})$

\subsubsection{Model COST 231 Walfisch-Ikegami}

Model Cost-231 Walfisch-Ikegami pada prinsipnya terdiri dari 3 elemen yaitu : freespace loss, rooftop-to-street diffranction and scatter loss, dan multiscreen loss [1].

$$
L P L=L f+L r s t+L m s
$$

Dimana, Lf : free-space loss

Lrts : rooftop-to-street diffranction and scatter loss

Lms : multiscreen loss

\subsection{Quantum-behaved Particle Swarm Optimization (QPSO)}

Dengan metode QPSO, keadaan partikel dikarakteristikan dengan fungsi gelombang wave function $\Psi(\mathrm{x}, \mathrm{t})$, bukan dalam fungsi posisi dan kecepatan. Parameter lain yang dikenal di dalam algoritma QPSO adalah contractionexpansion coefficient. Parameter ini digunakan untuk mengatur kecepatan konvergensi dari partikel. Nilai awal yang lebih tinggi dapat menghasilkan keragaman populasi yang lebih besar pada awal optimisasi, sedangkan pada tahap berikutnya nilai beta yang lebih rendah, membuat eksplorasi lebih terfokus dalam mencari ruang. Contraction-expansion coefficient disesuaikan dinamis selama optimisasi. Fungsi contraction-expansion coefficient dituliskan dalam persamaan[4]:

$\beta(t)=\beta \max -\left(\frac{\beta \text { max }-\beta \min }{\text { iter max }}\right) *$ iter $(t)$

\section{METODOLOGI}

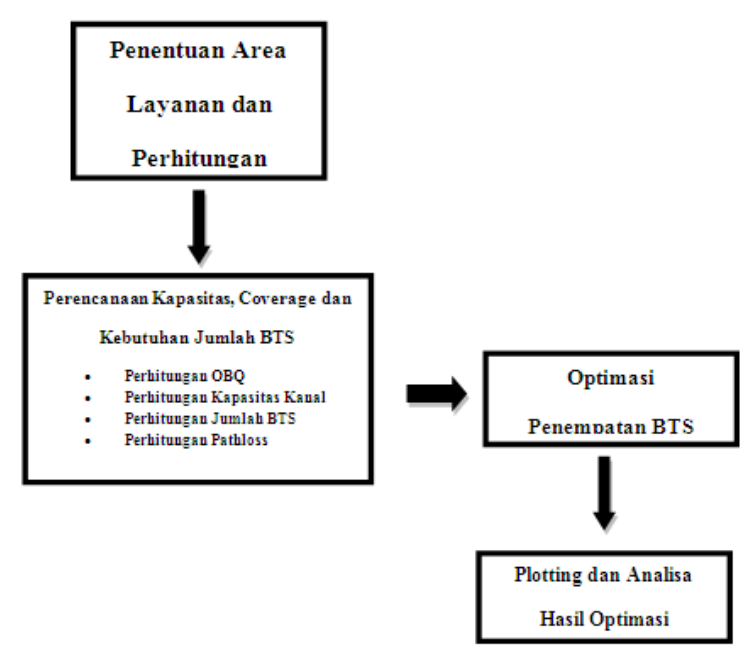

Gambar 1. Diagram Alir Kerangka Solusi Permasalahan

Tahapan penelitian ini berisi kerangka solusi permasalahan yang meliputi penentuan daerah layanan dan perhitungan jumlah pelanggan, perencanaan kapasitas dan coverage, dan pengoptimasian jaringan dengan menggunakan Quantum-behaved Particle Swarm Optimization, dan Plotting Hasil Simulasi. 
Tahapan kerangka solusi permasalahan ditunjukkan pada Gambar 1.

1. Penentuan daerah layanan dan Perhitungan Jumlah Pelanggan dilakukan dengan cara menentukan daerah layanan yang menjadi objek perencanaan. Langkah berikutnya adalah menghitung jumlah user yang berpotensi menggunakan jaringan UMTS.

2. Perencanaan kapasitas dan Coverage dilakukan menggunakan perencanaan jaringan komunikasi seluler.

3. Optimasi Penempatan BTS dilakukan dengan menggunakan QPSO untuk menempatkan BTS pada posisi baru. Performansi penempatan Node B ditentukan oleh daya cakup wilayah (coverage area) yang dihasilkan dan tingkat layanan trafik.

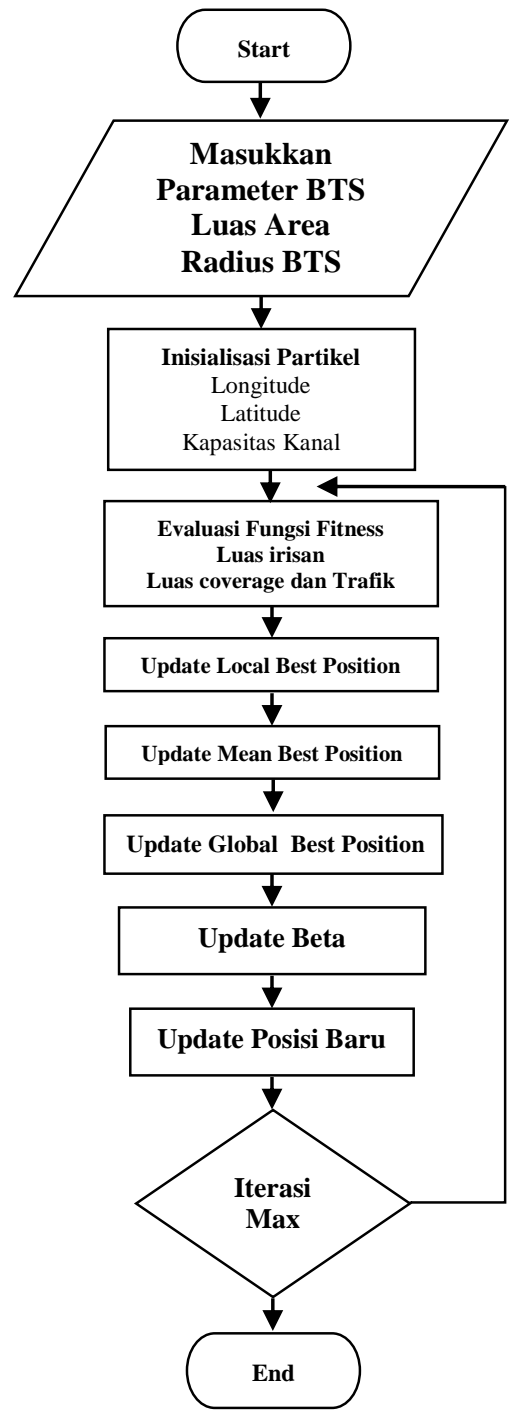

Gambar 2. Flowchart algoritma Q-PSO

\subsection{Inisialisasi Partikel dan Parameter BTS}

Inisialisasi partikel merupakan langkah awal yang dilakukan untuk memperoleh nilai optimal dengan menyebar partikel dengan posisi acak.

$$
\begin{aligned}
& x 1=\left(\begin{array}{lllllll}
x_{11} & x_{12} & x_{11} & \ldots \ldots \ldots . . & x_{1-\text { Jumlahpartikel }}
\end{array}\right) \\
& x 2=\left(\begin{array}{lllllll}
x_{21} & x_{22} & x_{11} & \ldots \ldots & \ldots . & x_{2-\text { Jumlahpartikel }}
\end{array}\right) \\
& x 3=\left(\begin{array}{llllll}
x_{31} & x_{32} & x_{33} & \ldots \ldots \ldots . . & x_{3-\text { Jumlahpartikel }}
\end{array}\right) \\
& x 4=\left(\begin{array}{llllll}
x_{41} & x_{42} & x_{43} & \ldots \ldots \ldots . . & x_{4-\text { Jumlahpartikel }}
\end{array}\right) \\
& \begin{array}{llllll}
\vdots & \vdots & \vdots & \vdots & \ddots & \vdots
\end{array} \\
& x n=\left(\begin{array}{lllllll}
x_{n 1} & x_{n 2} & a_{n 3} & \ldots & \ldots & \ldots & x_{n j u m l a h p a r t i k e l}
\end{array}\right)
\end{aligned}
$$

\subsection{Fungsi Fitnes}

Fungsi fitness dilakukan ketika partikel telah tersebar pada suatu posisi acak. Adapun fungsi fitness yang digunakan adalah [6]:

$$
\text { Fitnes }=\text { Coverage BTS }+ \text { Trafik BTS }
$$

Coverage BTS = Total luas coverage semua BTS - Total luas irisan

$$
\sum_{L}=\pi\left(r 1^{2}+r 2^{2}+r 3^{2}+r 4^{2} \ldots+r n^{2}\right)
$$

$$
\left\{\begin{array}{c}
\text { jika } i=j, L \cap_{i j}=0 \\
j i k a r_{1}+r_{2}<d_{i j}, L \cap_{i j}=0 \\
L \cap_{i j}=2 r_{1} r_{2} c 0 s-1\left(\frac{d}{2 r}\right)-d\left(r_{1}+r_{2}-\left(\frac{d^{2}}{4}\right)\right)
\end{array}\right.
$$

$$
\begin{gathered}
\text { Luas Coverage Total }=\sum L-\sum L \cap \\
\text { Presentase Coverage }=\frac{\text { Luas Coverage Total }}{\text { luas area perencanaan }} \times 100 \% \\
\text { Trafik }=\sum_{1}^{n} \text { trafik tiap sel } \\
\text { Trafik tiap sel }=\frac{\text { Kapasitas Kanal }\left(\frac{\text { Kbps }}{\text { sel }}\right) \times \text { Luas Sel }\left(\mathrm{Km}^{2}\right)}{\text { Kepadatan pengguna }\left(\frac{\text { user }}{\mathrm{Km}^{2}}\right)}
\end{gathered}
$$

Aturan (rule) pada Algoritma QPSO ini adalah : Apabila nilai irisan lebih kecil dari nilai Luas Coverage BTS, dan Apabila nilai fitness dari posisi yang baru lebih tinggi (optimum) dibandingkan dengan nilai fitness dari posisi yang lampau, maka posisi partikel yang ditetapkan adalah posisi yang baru.

\subsection{Menentukan Local Best Position}

Penentuan local best position adalah untuk partikel yang menghasilkan nilai fitness optimum. Optimum dapat berarti nilai maksimal maupun nilai minimal. 


\subsection{Perpindahan Partikel}

Pada kondisi ini partikel hanya berpindah untuk kurun waktu tertentu. Selama kurun waktu ini maka partikel akan melakukan evaluasi pada posisi yang baru sebelum menetapkan posisi partikel tetap.

\subsection{Evaluasi Iterasi-i}

Pada proses ini maka posisi partikel baru akan dievaluasi terlebih dahulu, tujuannya untuk mengatahui apakah posisi yang baru dapat menghasilkan nilai fitness yang lebih baik atau tidak . Melalui fungsi objektif yang ditetapkan maka akan diperoleh posisi yang baru.

\subsection{Update Posisi Iterasi-i}

Setelah dilakukan evaluasi pada posisi partikel yang baru, maka nilai fitness antara masing-masing partikel yang baru dan lalu dibandingkan satu sama lain. Apabila nilai fitness dari posisi yang baru lebih tinggi (optimum) dibandingkan dengan nilai fitness dari posisi yang lampau, maka posisi partikel yang ditetapkan adalah posisi yang baru. Namun apabila nilai fitness terakhir merupakan nilai yang lebih rendah (tidak optimum) dibandingkan dengan nilai fitness pada posisiyang lama maka posisi yang ditetapkan adalah yang lama.

\subsection{Update Global Best Position Iterasi-i}

Global best position diperoleh dengan membandingkan nilai dari local best fitness dari iterasi-i dengan iterasi i-1. Apabila nilai fitness untuk inisialisasi awal dan iterasi pertama samasama optimum pada partikel yang sama, maka local best fitness tetap menjadi milik partikel yang sama.

\section{HASIL DAN PEMBAHASAN}

\subsection{Penentuan Daerah Layanan}

Perencanaan jaringan UMTS ini akan diimplementasikan pada wilayah kota Malang dengan luas wilayah sebesar 110,06 Km2. Berdasarkan kepadatan penduduknya, wilayah kecamatan Sukun, Klojen, Blimbing dan Lowokwaru termasuk dalam jenis wilayah urban dengan luas wilayah sebesar 71,17 $\mathrm{Km}^{2}$. Sedangkan kecamatan Kedungkandang termasuk jenis wilayah suburban dengan luas wilayah sebesar $38,89 \mathrm{Km}^{2}$, dengan Jumlah BTS yang dimiliki oleh provider A sejumlah 55 BTS[8].

\subsection{Perhitungan Jumlah Pelanggan}

Persentase pertumbuhan penduduk kota Malang adalah sebesar $0.61 \%$ per tahun[7] dengan persentase penetrasi seluler adalah sebesar $85 \%$, dan penetrasi seluler provider A adalah 21,7\% [8], maka, didapatkan hasil perhitungan pada Tabel 1:

Tabel 1. Estimasi PenggunaTelepon Seluler

\begin{tabular}{|l|c|}
\hline Jumlah Penduduk Tahun 2014 & 845.973 \\
\hline Penetrasi Seluler (85\%) & 719.077 \\
\hline $\begin{array}{l}\text { Penetrasi Seluler Untuk } \\
\text { Provider A (21 \% dari 85 \%) }\end{array}$ & 151.006 \\
\hline
\end{tabular}

Diasumsikan penetrasi UMTS (persentase pengguna jaringan UMTS) pada tahun 2020 untuk daerah urban sebesar 55\% [1], dan penetrasi 3G untuk daerah suburban sebesar 25\% [1]. Dengan asumsi tersebut maka jumlah pengguna layanan $3 \mathrm{G}$ di Kota Malang pada tahun 2020 untuk wilayah urban dan suburban berturut turut adalah sebesar 86.140 dan 39.154 user.

\subsection{Perhitungan $O B Q$}

\subsubsection{OBQ Untuk Wilayah Urban}

Perhitungan OBQ di wilayan urban dapat dilakukan dengan menggunakan persamaan 2, Maka dapat perhitungan OBQ wilayah suburban adalah sebesar $1405 \mathrm{Kbps} / \mathrm{Km}^{2}$.

\subsubsection{OBQ Untuk Wilayah Suburban}

Perhitungan OBQ di wilayan Suburban dapat dilakukan dengan menggunakan persamaan 2, Maka dapat perhitungan OBQ wilayah suburban adalah sebesar $510 \mathrm{Kbps} / \mathrm{km}^{2}$ :

\subsection{Perhitungan Kapasitas kanal}

Berdasarkan persamaan 3, maka dapat dihitung kapasitas yang disediakan sistem dengan data: Bit rate $(\mathrm{R})=384 \mathrm{Kbps}$, Energy bit per noise $(\mathrm{Eb} / \mathrm{No})=1 \mathrm{~dB}=1,2589$, Bandwidth $(\mathrm{W})=3,84 \mathrm{MHz}$, Activity factor $(\alpha)=1$, agar dapat mengakomodasi layanan suara dan data. Gain sektorisasi antena $(\beta)=2,4$. Dan Faktor interferensi $(f)=0,6$. Sehingga diperoleh kapasitas/jumlah kanal adalah sebesar 11,9145 $\mathrm{kanal} / \mathrm{sel}$ atau 4575,168 $\mathrm{Kbps} / \mathrm{sel}$. Dengan pembebanan acuan awal 60\%, maka kapasitas yang disediakan sistem adalah sebesar 2745,1 Kbps/sel. 


\subsection{Perhitungan Jumlah Sel}

Luas coverage area urban dengan menggunakan persamaan 4 adalah sebesar 1,95 $\mathrm{Km}^{2} / \mathrm{sel}$, dan luas coverage area suburban adalah sebesar $5,38 \mathrm{Km}^{2} / \mathrm{sel}$. Sehingga didapatkan jumlah Node $B$ yang dibutuhkan untuk wilayah urban adalah sebanyak 36 Node $B$ dengan radius sel $0,79 \mathrm{Km}$ dan jumlah Node $B$ yang dibutuhkan untuk wilayah suburban adalah sebanyak 7 Node $B$ dengan radius sel 1,30 Km.

\subsection{Perhitungan Path Loss}

Dengan menggunakan model propagasi Hata-Okumura (Persamaan 7) , diasumsikan spesifikasi perancangan jaringan di daerah suburban adalah sebagai berikut [1]:

- Frekuensi $(\mathrm{fc})=900 \mathrm{Mhz}$

- $\operatorname{Radius~sel~(d)=0,79~Km~(urban),~dan~}$ $1,36 \mathrm{Km}$ (suburban)

- Base station antenna height $(\mathrm{hb})=30 \mathrm{~m}$

- Mobile antenna height $(\mathrm{hm})=1,5 \mathrm{~m}$

Besarnya path loss dengan menggunakan model propagasi Hata-Okumura secara berturutturut adalah 121,51 dB untuk wilayah urban dan $137,41 \mathrm{~dB}$ untuk wilayah suburban. Nilai MAPL (Maximum Allowable Path Loss) adalah 159 $\mathrm{dB}[1]$. Terlihat bahwa nilai MAPL lebih besar dari path loss, maka perencanaan jaringan $3 \mathrm{G}$ ini dapat diimplementasikan.

\subsection{Hasil Optimasi Jaringan dengan Quantum-Behaved Particle Swarm Optimization}

\subsubsection{Wilayah Urban}

Setelah dilakukan 10 kali percoban, didapatkan $76.2304 \%$ coverage $16.3592 \mathrm{Km}^{2}$ irisan, dan 157,8475 Trafik.

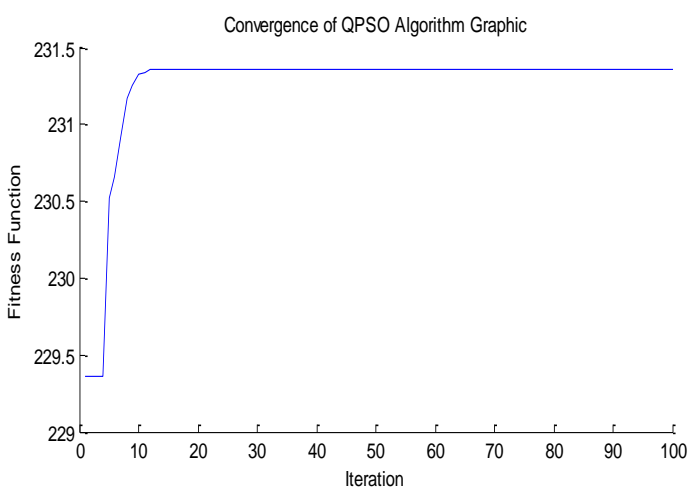

Gambar 3. Nilai Fitness Optimasi Wilayah Urban
Gambar 3 menunjukkan nilai fitness mencapai konvergen pada iterasi ke-13 dimana susunan BTS terpilih dari Global best position menghasilkan fitness sebesar 231,3621. Hasil dari optimasi kemudaian di plot menggunakan google earth.

\subsubsection{Wilayah Suburban}

Setelah dilakukan 10 kali percoban, diapatkan 6,1698 $\mathrm{Km}^{2}$ luas irisan, 88,7667\% coverage, dan 113,8412 trafik, dengan Global Best Position sebesar Untuk susunan BTS nya adalah sebagai berikut :

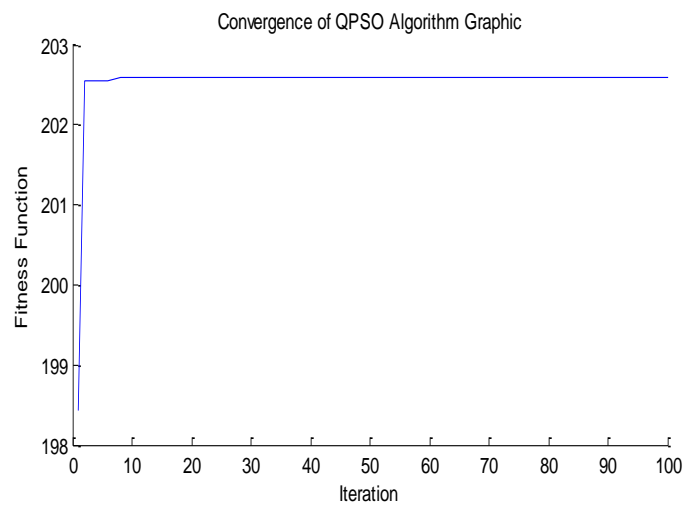

Gambar 4. Nilai Fitness Optimasi Wilayah Urban

Gambar 4 menunjukkan nilai fitness mencapai konvergen pada iterasi ke-5 dimana susunan BTS terpilih dari Global Best Position menghasilkan total fitness 202,5934. Hasil dari optimasi kemudian di plot menggunakan google earth.

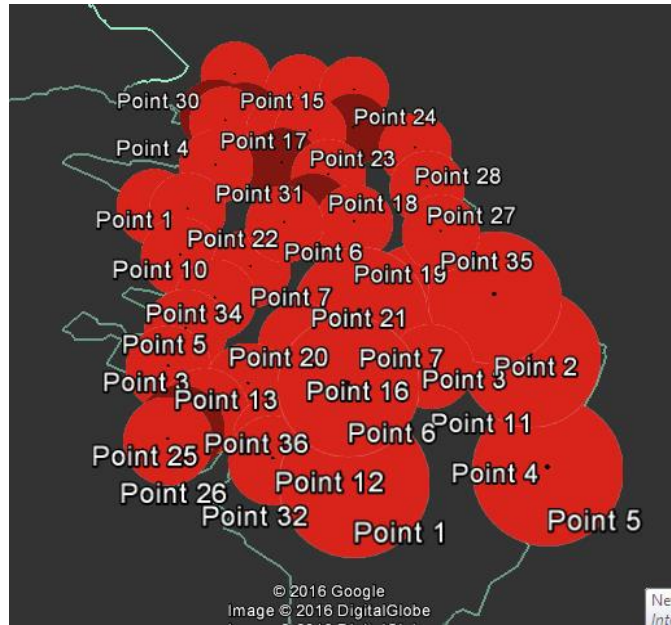

Gambar 5. Hasil plotting pada google earth 
Dari Gambar 5, dapat diketahui bahwa masih ada blankspot di beberapa titik. Pada wilayah urban, setiap kecamatan memiliki blankspot dengan nilai yang kecil. Namun pada wilayah suburban masih terdapat blankspot dikarenakan posisi BTS yang berdekatan dan jumlah BTS existing pada wilayah urban mengalami kekurangan.

\section{KESIMPULAN}

Berdasarkan hasil dari proses dan pembahasan yang telah dilakukan dapat disimpulkan sebagai berikut :

1. Algorithma QPSO dapat digunakan untuk optimasi BTS dengan parameter posisi BTS (longitude, latitude) dan kapasitas kanal dimana dari 10 percobaan dihasilkan susunan Menara BTS yang mempunyai $76.2304 \%$ (urban) , 88,7667 \% (suburban) dari luas perencanaan coverage serta 157,8475 (urban) 113,8412 trafik (suburban) dan dengan total fitness 234,0778 (urban) dan 202,5934 (suburban).

2. Berdasarkan data dari provider A, optimasi menggunakan algoritma Quantum-behaved Particle Swarm Optimization dapat mengurangi jumlah BTS dari 55 BTS menjadi 43 BTS dengan mengganti posisi BTS dengan posisi baru.

3. Masih Terdapat blankspot pada beberapa titik.

\section{DAFTAR PUSTAKA}

[1] P. D. Aryanti, S. H. Pramono, and O. Setyawati, "Optimasi Penempatan Node B UMTS900 pada BTS Existing Menggunakan Algoritma Genetika," $J$. EECCIS, vol. 7, no. 2, p. pp-111, 2014.

[2] M. I. Rusydi, "Optimasi Pengendali PID pada Pesawat Autopilot Berbasiskan Algoritma Genetika," J. Nas. Tek. ELEKTRO, vol. 5, no. 2, 2016.

[3] S. T. Rini Nur Hasanah and others, "Optimasi Penempatan dan Kapasitas Multi FACTS Devices pada Sistem Tenaga Listrik Menggunakan Metode Particle Swarm Optimization (PSO)," $J$. Mhs. TEUB, vol. 2, no. 3, 2014.

[4] J. Li, "Improved Quantum-Behaved Particle Swarm Optimization," Open J. Appl. Sci., vol. 5, no. 6, p. 240, 2015.
[5] Y. Sugiyanto, Arsitektur Jaringan UMTS. MobileIndonesia. net| Sharing Knowledge, Sharing Information, 2007.

[6] M. Fachrie, S. Widowati, and A. T. Hanuranto, "Implementasi Fuzzy Evolutionary Algorithms Untuk Penentuan Posisi Base Transceiver Station (BTS)," in Seminar Nasional Aplikasi Teknologi Informasi (SNATI), 2012.

[7] "Kota Malang Dalam Angka 2015," Scribd. [Online]. Available: https://www.scribd.com/doc/314353435/ Kota-Malang-Dalam-Angka-2015.

[Accessed: 29-Jul-2016].

[8] "Selamat Datang. PT Indosat Tbk Paparan Publik Tahun 2014.” [Online]. Available: http://docplayer.info/364460-Selamatdatang-pt-indosat-tbk-paparan-publiktahun-2014.html. [Accessed: 29-Jul2016].

\section{Biodata Penulis}

Moh Fatkhur Rohman, Tempat dan Tanggal Lahir: Malang, 27 Oktober 1992. Alamat: Bunut Wetan Kec. Pakis Kab. Malang Jawa Timur. Email : fatkhurrohman.mohamad@gmail.com 